\title{
Design and Implementation of Electricity Fault Detection System Using Microcontroller Arduino UNO
}

\author{
Chandra Adrian and Mia Galina \\ Study Program of Electrical Engineering, President University, Bekasi 17550, Indonesia \\ Corresponding author: miagalina@ president.ac.id
}

\begin{abstract}
This paper concentrates of creating a fault detection system that detect both emergency fault and fault that need of maintenance with prototype of electrical installation that is done through manual simulation method. The prototype consists of the lamp as the load integrated with Arduino UNO as the microcontroller with GSM module and buzzer. The microcontroller will detect and deduce the type of the fault happened in the installation and will send the data of the fault through the GSM module. GSM module then transmits the data to the mobile phone and let the user aware of the fault. Also, there will be buzzer as the warning system by producing high pitch sound that signalizes the fault that need immediate handling or emergency. The data of both faults will be sent as Short Message Service (SMS) to the user. The SMS will give the user the type of fault either emergency or need of maintenance, happened in the installation.
\end{abstract}

Keywords: fault detection, GSM module, Short Message Service

\section{INTRODUCTION}

Every household nowadays are fully embedded with electricity installation, mainly used for home appliances that require electricity. In using electricity, some faults may be encountered although it is unwanted. While there are many variants of fault that can be happen, most of them come all of the sudden that it is possible for the household members do not know the fault at all. Because of that issue, there needs to be some kind of detection that can warn the household member about the fault.

To make the detection told in efficient and practical way, it needs to be embedded with the device that surely all the members used frequently. One such device is mobile phone which surely vital and mainly used for communication although nowadays there are many features that make the mobile phone seems inseparable from human life. With that advantage, the detection can be sent through Short Message Service (SMS) feature in mobile phones and the members can easily get the information of the electricity fault.

Additional feature of detection is also implemented if there is a special case which mobile phone are rendered useless. This second detection in form of the buzzing alarm can make the members more aware of the fault and can help to warn other people too if the members are not present in the home. Electricity in the home installation would encounter any faults, which is the main reason why there should be any automatic detection that can warn the house members to prevent any unwanted damage. In terms of home electricity installation, some faults may be encountered although it is unwanted. While there are many variants of fault that can be happen, most of them come all of the sudden that it is possible for the household members do not know the fault at all. Because of that issue, there needs to be some kind of detection that can warn the household member about the fault.

This paper will be focusing on designing a prototype which is based on home electric installation concept, capable to detect and deduce the electricity fault from mobile phone. The objective of this paper is to design a prototype of home electric installation system embedded with the fault detection system that detects the voltage problem fault, short circuit fault and broken component fault by sending SMS to the user. By connecting the system to the mobile phones function, the members can easily get the information of the electricity fault. Additional feature of detection also implemented if there is a special case which mobile phone are rendered useless. This second detection in form of the buzzing alarm can make the members more aware of the fault and can help to warn other people too if the members are not present in the home.

\section{LITERATURE REVIEW AND DESIGN SPECIFICATIONS}

Electricity faults in home installation are often occurred without any symptoms and thus prolonged faults can resulted in major problem. Some faults are not considered serious that it can spread into another area, while others need any immediate actions to prevent the faults become huge disadvantage. Fault itself is an erroneous state of software or 
hardware that resulted in the failure of its system [1]. There are various sources for fault to be present. From design errors, external disturbances, long time duration and human errors.

Before the faults need to be corrected, it is imperative to be detected first and diagnosed the type of the fault. There are methods to detect and diagnose the faults in the various installations. Nyberg [2] suggested. The model-based fault diagnosis system that also suitable with complex installations with many advantages such as it can be performed in larger operating range, possibilities to perform isolation and disturbance compensation. Nilsson [3] presents the fault detection in photovoltaic systems particularly in solar cell system.

In the end, fault detection system suggests the independence of the system to configure the presence of the fault and minimize the fault effects. In the case of home installation, this would lead to home automation system. In this study [4], it suggested the home automation system with the usage of Arduino, thus striving to become a smart home installation. Fault detection principle can be fitted and added to this smart home installation.

\section{A. Microcontroller Arduino UNO R3}

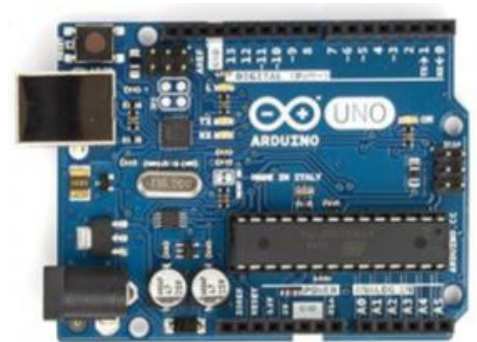

Figure 1. Arduino UNO R3 Microcontroller

Arduino UNO R3 is a microcontroller board which utilizes Atmega328 chip. The I/O pins of Arduino UNO R3 are 6 analog pins and 14 digital pins. Arduino UNO has sufficient pins for this prototype. The pins of Arduino UNO can be divided by 3 parts. There are power pins, analog pins, digital pins with the PWM (Pulse Width Modulator), IOREF Pin, and AREF pin.

There are 4 built-in LED in Arduino UNO board. There are ON LED, RX LED, TX LED and L LED. Arduino UNO $\mathrm{R} 3$ have a reset button that used to reset the program that working in the Arduino and makes it start again from the beginning. It also has RX pin (pin in 0 value), the pin itself means receive TTL serial data. TX pin (pin in 1 value), the pin itself means transfer TTL serial data.

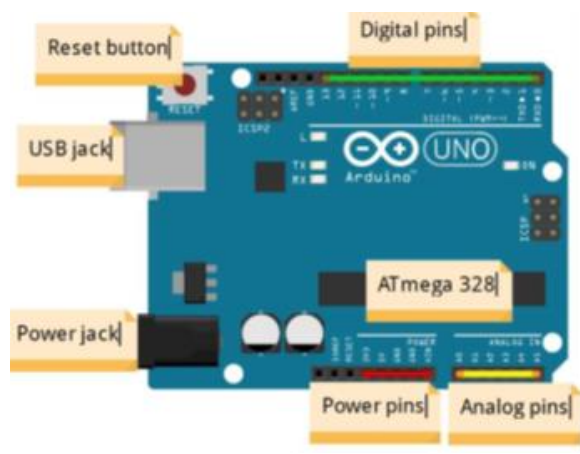

Figure 2. Arduino UNO R3 pin configuration

\section{B. Microcontroller Arduino UNO R3}

The software used in this prototype is Arduino IDE (Integrated Development Environment) 1.0.5. The Arduino IDE interface can be seen in following the Figure 3 below.

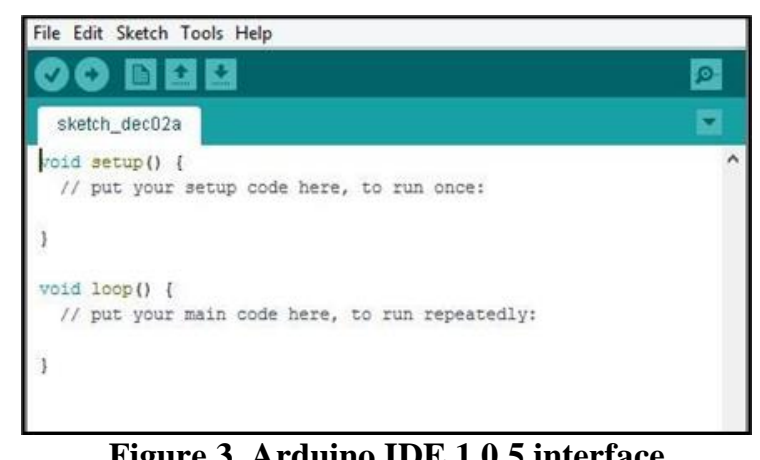

Figure 3. Arduino IDE 1.0.5 interface

\section{ACS-712 Current Sensor}

ACS-712 is used to sense current flow for both AC and DC signals. This sensor gives an output of an analog voltage signal linearly with the current sensed. The sensor requires $5 \mathrm{~V}$ to operate. Table 1 below is the ACS-712 specification [6].

Table 1. ACS-712 Specification

\begin{tabular}{|c|c|c|c|}
\hline Specifications & \multicolumn{3}{|c|}{ Descriptions } \\
\hline Type & 5 A Module & $20 \mathrm{~A}$ Module & $30 \mathrm{~A}$ Module \\
\hline Supply Voltage & $5 \mathrm{VDC}$ & $5 \mathrm{VDC}$ & $5 \mathrm{VDC}$ \\
\hline Range & -5 to $+5 \mathrm{~A}$ & -20 to $+20 \mathrm{~A}$ & -30 to $+30 \mathrm{~A}$ \\
\hline & $\mathrm{VCC} / 2 \cong 2.5$ & $\mathrm{VCC} / 2 \cong 2.5$ & $\mathrm{VCC} / 2 \cong 2.5$ \\
Voltage at $0 \mathrm{~A}$ & $\mathrm{VDC}$ & $\mathrm{VDC}$ & $\mathrm{VDC}$ \\
\hline Scale Factor & $185 \mathrm{mV} / \mathrm{A}$ & $100 \mathrm{mV} / \mathrm{A}$ & $66 \mathrm{mV} / \mathrm{A}$ \\
\hline
\end{tabular}

The IC contains a conductive material across which a measurable voltage produces when an electric current is flowing through the conductor. Applied current flowing through this copper conduction path generates a magnetic field which the Hall IC converts into a proportional voltage. 


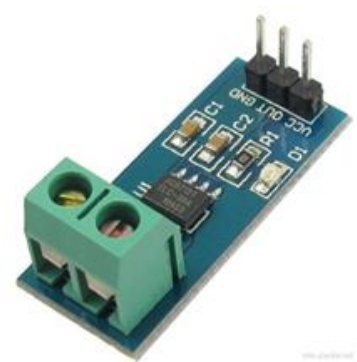

Figure 4. ACS-712 current sensor module

The prototype used $20 \mathrm{~A}$ module which means the maximum current flowing through the sensor is $20 \mathrm{~A}$ where the output voltage at the output pin varies linearly from 2.5 $\mathrm{V}$ with source of 5 VDC $(1 / 2 \times$ VCC). When output voltage is around $2.5 \mathrm{~V}$, it indicates there is no current flowing. The module has two terminals for measurement which are common and output, they are connected in series. There are also three pin which are VCC and GND pin to activate the module and OUT pin which represent the value of current measured in voltage.

\section{Voltage Sensor}

Voltage sensor is a device which capable to measure voltage. It is commonly a voltage divider. Figure 5 below shows Resistor R1 and R2 are connected in series with voltage source and the output voltage is measured on the R2. The voltage source will be converted into a voltage value that can be read by the microcontroller in the range of 0 to 5 Volt. Then, the microcontroller will read the input as digital value.

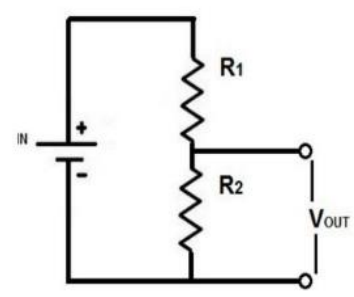

Figure 5. Voltage divider circuit

Figure 6 shows the voltage sensor module. It has two power terminals which will be connected to the VCC and GND. In the other side, there are three pins which connect to the microcontroller. Pin $\mathrm{S}$ is connected to the analog input, pin (+) is connected to the power $5 \mathrm{~V}$ pin, and the pin $(-)$ is connected to the GND pin.

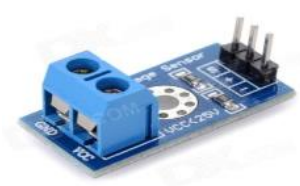

Figure 6. Voltage sensor module

\section{E. GSM module}

GSM module is a chip that will be used to establish communication between a mobile device or a computing machine and a GSM or GPRS system. It is integrated with the system as an embedded software piece. This module can send and receive the data via Short Message Service (SMS) through mobile phone. Figure 7 shows the GSM module SIM800L. It has 12 pins divided by 2 in each side. 2 pins connected to Vcc $(3.7-4.2 \mathrm{~V})$ and GND.

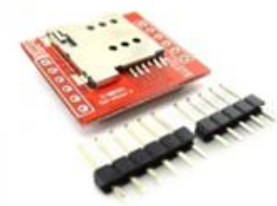

Figure 7. GSM module SLM800L

\section{F. Buzzer}

Buzzer $5 \mathrm{~V}$ is the electric component that give voice or high pitch sound notification. This buzzer is connected to the microcontroller Arduino UNO and will act as the warning system of the prototype.

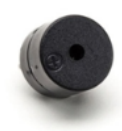

Figure 8. Buzzer 5 Volt

\section{G. LCD (Liquid Crystal Display)}

LCD-1602 is a one of the most commonly used display modules especially for Arduino. This display module has 16 columns and 2 lines. It has blue backlight which contrast can be adjusted. The screen resolution is $64.5 \mathrm{~mm} \times 16 \mathrm{~mm}$. LCD-1602 has 7 I/O pins which will be connected to the microcontroller 


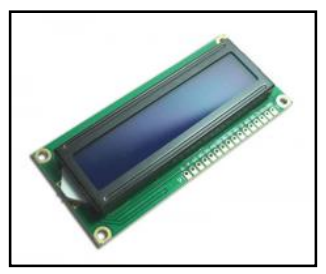

Figure 9. LCD 16x2

\section{H. Relay Module}

Relay module is a compact size of a relay with connection pin. It is an electrical component which has control system It acts as an automatic switch which is controlled by the program. A relay consists of an induction part. This induction part is able to reflect variable inputs such as current, voltage, pressure, frequency etc.

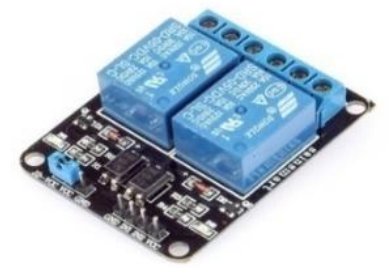

\section{Figure 10. Two-channel relay module}

\section{DESIGN AND IMPLEMENTATION}

The general work procedure is the first part to be explained in block diagram followed by the flowchart of the whole system, the requirement of components, the hardware design and lastly with the software implementation which consists of Arduino program coding.

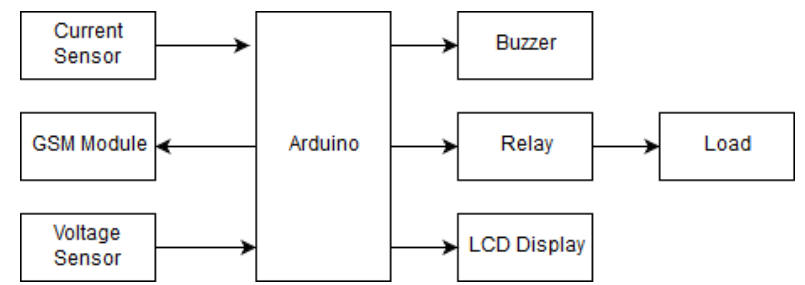

Figure 11. Block diagram of sytem

The block diagram of the system as described on the figure above. The current sensor and voltage sensor will measure the current and voltage driven in the installation and send the data to Arduino UNO as the microcontroller. The relay also sends the data to Arduino based on the switching state in the installation. Arduino then read and processed the data. If there is any fault and irregularity based on the data from current sensor, voltage sensor and relay, it will send the fault notification to mobile phone in Short Message
Service (SMS) format via GSM module. Arduino also trigger the buzzer on as a warning system. Figure 12 below shows the overall flowchart of the system.

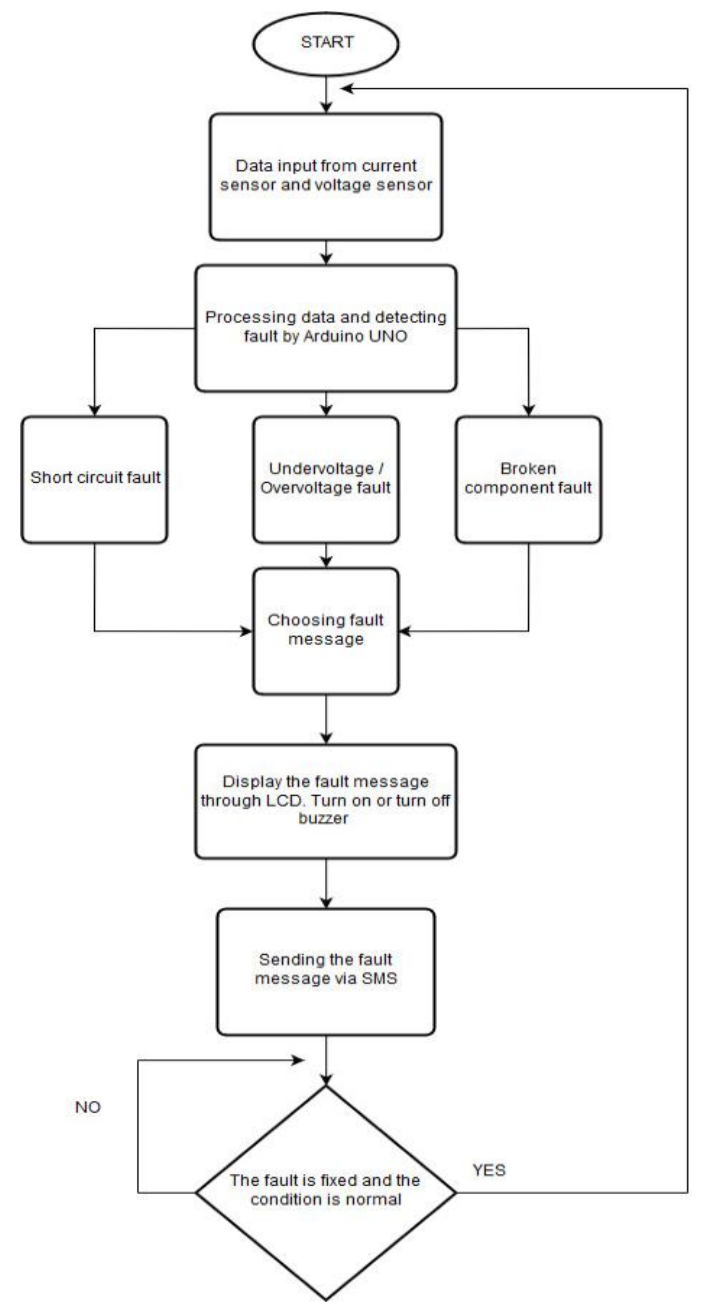

Figure 12. Overall flowchart of the installation

\section{A. Hardware Design}

The prototype consists of the box made of square wood. The box is not fully enclosed as the top of the box can be lifted to open the box and give insight of the circuit as described by figure 13 below.

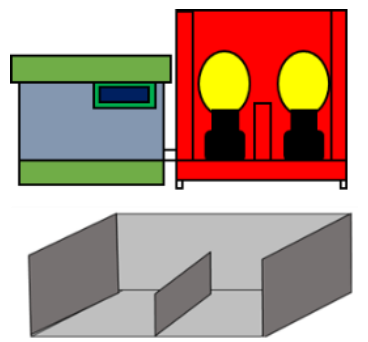

Figure 13. Design of prototype 


\section{B. Hardware Implementation}

This part explains how the prototype is built. The components required in the hardware development of the prototype are.

1. A box made of square wood as the prototype shell.

2. 1 Arduino UNO as the microcontroller device.

3. 2 ACS-712 current sensors as the input measurement of current to microcontroller.

4. 1 Voltage Sensor as the input measurement of voltage to microcontroller.

5. 1 Two Channel Relay module as the switch to control the voltage $220 \mathrm{~V}$ of the installation.

6. 1 SIM800L GSM module to transmit the measured data to the mobile phone.

7. 1 Buzzer to give a high pitch sound notification.

8. 2 Fitting lamp, 2 DC LED lamp, and electric switch for the prototype installation.

9. 1 Power Supply as the power source for the prototype.

10. 1 LCD display that show the type of fault in the prototype.

\section{Electrical Design}

The prototype will have the direct current (DC) installation with the normal supply voltage range $11.4 \mathrm{~V}-$ 13.5V. Figure 14 below show the schematic diagram of the power installation wiring without the output component.

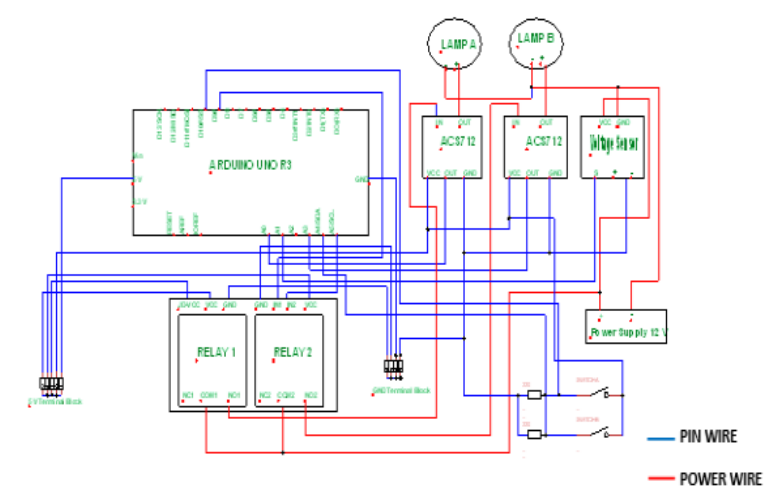

Figure 14. Power input wiring schematic diagram

From the schematic, it is shown that the current sensor and the voltage sensor detect the current and voltage value from the power supply and through the load. The data will be processed in Arduino as the microcontroller in form of analog data.

Arduino UNO as the microcontroller process the input of current and voltage from the respective sensors in analog data and give the output to the GSM Module, LCD display and buzzer in form of digital or binary data. Based on the value of current and the voltage from the installation, Arduino can give the suitable fault notification to the user.

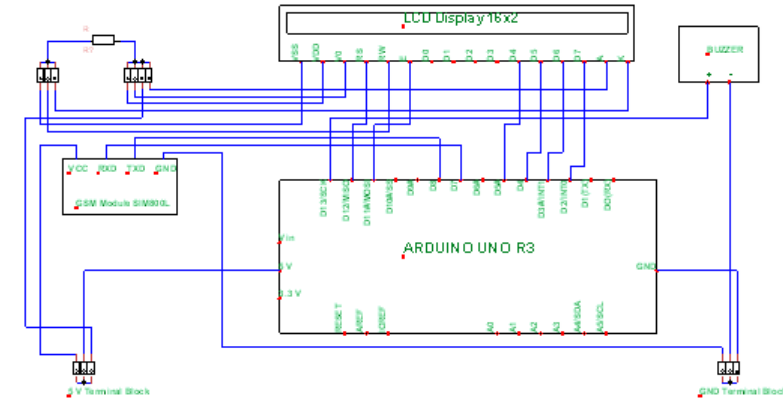

Figure 15. Output wiring schematic diagram

\section{Fault Detection Design}

The device will check whether the voltage is suitable with the value of the set of supply voltage. The measurement will be done by the voltage sensor, converting 0-25 VDC from power supply into 0-5 VDC to Arduino UNO. If the voltage is not suitable then it won't allow relay to be operating and sending the fault message, if the voltage is suitable then it allows the relay to be operating. The range of the voltage that be used in the installation are:

1. Under Voltage : below $11.5 \mathrm{~V}(<11.5 \mathrm{~V})$

2. Normal Voltage : $11.5 \mathrm{~V}-14 \mathrm{~V}$

3. Over Voltage : above $14 \mathrm{~V}(>14 \mathrm{~V})$

The minimum normal range operation is determined by the standard voltage drop of 5\% of the operating value [7] while the maximum normal range operation is $15 \%$ from operating value.

\section{E. Software Design}

To implement the program to the microcontroller, the author used Arduino IDE 1.0.5. The program will consist of voltage and current measurement, $\mathrm{V}$ and A calculation, LCD display, serial display, and serial communication control.

\section{EXPERIMENTAL RESULT AND DISCUSSION}

The prototype is designed to control and detect the electric faults which are both emergency (under voltage, overvoltage and short circuit current) and maintenance fault (component broken) in the electrical installation via Short Message Service (SMS) communication to the mobile phone using GSM module. The prototype is able to detect and prevent if the voltage is not suitable with the system, also giving the information through SMS and turning on buzzer. It is also able to detect if the component is broken/unplugged while operating and also giving information through SMS but without turning on buzzer. For the case of the short circuit current, simulation is done through the switch that trigger short circuit before the relay process it. 
Short circuit current fault is detected if there is an over current happened in the installation. This fault can be simulated by using the red switch that connected directly with the two loads and connect the phase pin to the neutral pin in the switch. Component broken fault is detected if only the component is broken while operating.

The program will create an algorithm if the relay is on and suddenly the current is not detected on the circuit it will be detected as "Component broken" fault. This fault can be simulated by loosening the lamp fitting that trigger the installation to recognize it as the drop of current to 0 . Thus, the installation deduces the load as the component broken.
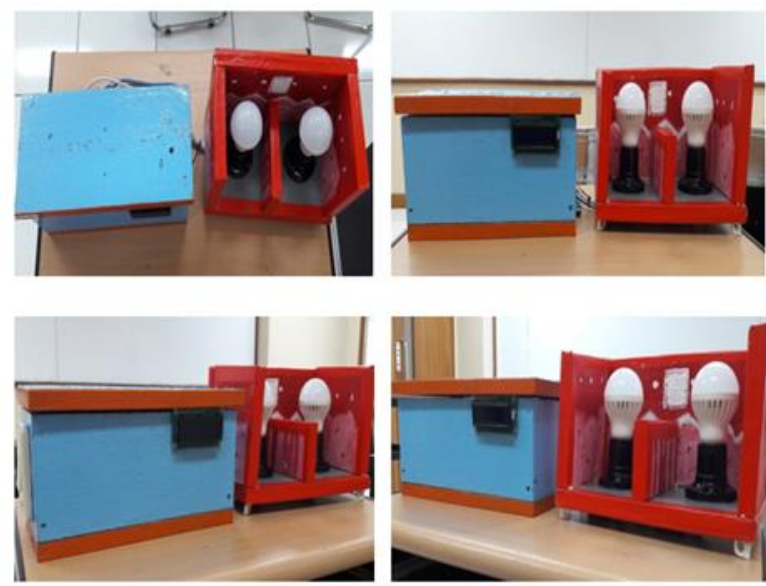

Figure 16. Hardware construction

The result is based on the simulation scenario in causing the fault to be detected and the indicators that define the classification of the fault that is send to the mobile phone. Table 2 below shows whether the final result is worked as the program implemented on the Arduino.

Table 2. Simulation and Testing Result

\begin{tabular}{|c|c|c|c|c|c|c|c|c|}
\hline Simulator & $v$ & I & Relay & $\begin{array}{c}\text { Type of } \\
\text { Fault }\end{array}$ & SMIS Read & LCD Display & $\begin{array}{l}\text { Buner } \\
\text { Status }\end{array}$ & Conclusion \\
\hline \multirow{3}{*}{$\begin{array}{l}\text { Power } \\
\text { Supply } \\
\text { Voltage }\end{array}$} & $\stackrel{<11.5}{\mathrm{~V}}$ & - & OFF & $\begin{array}{l}\text { Under } \\
\text { Voltage }\end{array}$ & $\begin{array}{l}\text { "The supply } \\
\text { voltage is sot } \\
\text { sutable" }\end{array}$ & $\begin{array}{l}\text { FAULT DETECTED } \\
\text { "UNDERVOLTAGE" }\end{array}$ & ON & \multirow{3}{*}{$\begin{array}{c}{[\sqrt{ }]} \\
\text { Accepted } \\
{[]} \\
\text { Rejected }\end{array}$} \\
\hline & $\begin{array}{l}11.5 \mathrm{~V} \\
<\mathrm{V}< \\
14 \mathrm{~V}\end{array}$ & $\begin{array}{c}0.09< \\
1< \\
0.15 \\
\text { and } \\
0.47< \\
1< \\
0.55\end{array}$ & oN & - & 然 & - & $\begin{array}{l}\text { OFF } \\
\text { (No } \\
\text { Fault) }\end{array}$ & \\
\hline & $>14 \mathrm{~V}$ & - & OFF & Oree Voltage & $\begin{array}{l}\text { "The supply } \\
\text { voltage is not } \\
\text { suitable" }\end{array}$ & $\begin{array}{l}\text { FAULT DETECTED } \\
\text { "OVERVOLTAGE" }\end{array}$ & ON & \\
\hline $\begin{array}{l}\text { Load } \\
\text { current } \\
\text { and Red } \\
\text { Switch }\end{array}$ & $\begin{array}{l}-0.25 \\
V<V \\
<4 V\end{array}$ & $\stackrel{-1.05}{A}$ & OFF & $\begin{array}{l}\text { Short Circuit } \\
\text { Current }\end{array}$ & $\begin{array}{l}\text { "There is a Short } \\
\text { Circuit current in } \\
\text { the circuit" }\end{array}$ & $\begin{array}{l}\text { FAULT DETECTED } \\
\text { "SHORT CIRCUIT" }\end{array}$ & oN & $\begin{array}{c}{[\sqrt{ }]} \\
\text { Accepted } \\
{[1]} \\
\text { Rejected }\end{array}$ \\
\hline $\begin{array}{c}\text { Load (DC } \\
\text { LED 12V) } \\
\text { at Fitting } \\
1 \\
\end{array}$ & $\begin{array}{l}11.5 \mathrm{~V} \\
<\mathrm{V}< \\
14 \mathrm{~V}\end{array}$ & $\begin{array}{c}0.09< \\
1< \\
0.15 \\
\text { then } 0 \\
\end{array}$ & ON & $\begin{array}{l}\text { Component } \\
\text { Broken }\end{array}$ & $\begin{array}{c}\text { "Component is } \\
\text { broken unplugged } \\
\text { impropely in } \\
\text { Point 1" }\end{array}$ & $\begin{array}{l}\text { FAULT DETECTED } \\
\text { "COMPONENT } \\
\text { BROKEN" }\end{array}$ & OFF & $\begin{array}{c}\sqrt{ }] \\
\text { Accepted } \\
1] \\
\text { Rejected } \\
\end{array}$ \\
\hline $\begin{array}{c}\text { Load (DC } \\
\text { LED 12V) } \\
\text { at Fitting } \\
2 \\
\end{array}$ & $\begin{array}{l}11.5 \mathrm{~V} \\
<\mathrm{V}< \\
14 \mathrm{~V}\end{array}$ & $\begin{array}{c}0.47< \\
1< \\
0.55 \\
\text { then } 0\end{array}$ & oN & $\begin{array}{c}\text { Component } \\
\text { Broken }\end{array}$ & $\begin{array}{c}\text { "Component is } \\
\text { broken unplugged } \\
\text { impropetly in } \\
\text { Point } 2 "\end{array}$ & $\begin{array}{l}\text { FAULT DETECTED } \\
\text { "COMPONENT } \\
\text { BROKEN" }\end{array}$ & OFF & $\begin{array}{c}{[\sqrt{ }]} \\
\text { Accepted } \\
{[1]} \\
\text { Rejected } \\
\end{array}$ \\
\hline
\end{tabular}

\section{Conclusion}

Based on the experiments and analysis of this Electricity Fault Detection System Using Microcontroller Arduino UNO, there are conclusions that can be presented:

1. Arduino UNO, GSM Module and Buzzer alarm are properly installed in the prototype and implemented as the control system to detect the fault in the prototype. This proves that the components can be used as the automatic detection system that can warn the house members to prevent any unwanted damage.

2. Arduino UNO successfully detect both emergency fault and maintenance fault and also send the data through GSM Module and also trigger the buzzer alarm for the emergency fault.

The prototype able to simulate the overvoltage/undervoltage fault, short circuit current and broken component fault with the scenario given in previous chapter. The fault is successfully detected and the data is send through SMS and also trigger buzzer alarm special for emergency case.

\section{REFERENCE}

[1] B. Franke, Embedded System. Lecture 9, Topic: "Reliability \& fault tolerance", School of Informatics, University of Edinburgh, Edinburgh, Scotland.

[2] M. Nyberg, "Model based fault diagnosis methods, theory, and automotive engine applications", Ph.D. dissertation, Dept. Elect. Eng., Linkoping University, Linkoping, Sweden, 1999.

[3] D. Nilsson, "Fault detection in photovoltaic systems", M.Sc. thesis, KTH Computer Science and Communication, KTH Royal Institute of Technology, Stockholm, Sweden, 2014.

[4] N. David, A. Chima, A. Ugochukwu, and E. Obinna. "Design of a home automation system using Arduino”, International Journal of Scientific \& Engineering Research, vol. 6, pp. 795801, June 2015.

[5] Arduino. Arduino UNO R3, 2015. [Online] https://www.Arduino.cc/en/Reference/HomePage. [Accessed September 5, 2016].

[6] Inc. Allegro MicroSystems, ACS712 Hall Effect Current Sensor, 2007.

[7] F Suryatmo, Dasar Dasar Teknik Listrik. Jakarta: Bina Adiaksara, 2005 